\title{
An Oncolytic Adenovirus Encoding SA-4-1BBL Adjuvant Fused to HPV-16 E7 Antigen Produces a Specific Antitumor Effect in a Cancer Mouse Model
}

\author{
Alejandra G. Martinez-Perez ${ }^{1,+}$, Jose J. Perez-Trujillo ${ }^{1,+}$, Rodolfo Garza-Morales ${ }^{2}$ (D, Norma E. Ramirez-Avila ${ }^{1}$, \\ Maria J. Loera-Arias ${ }^{1}$, Jorge G. Gomez-Gutierrez ${ }^{2}$ D, Odila Saucedo-Cardenas ${ }^{1,3}$, Aracely Garcia-Garcia ${ }^{1}$, \\ Humberto Rodriguez-Rocha ${ }^{1}$ and Roberto Montes-de-Oca-Luna ${ }^{1, *}$
}

1 Department of Histology, School of Medicine, Autonomous University of Nuevo León, Monterrey, NL 64460, Mexico; alejandra.martinezpr@uanl.edu.mx (A.G.M.-P.); jperez.me0052@uanl.edu.mx (J.J.P.-T.); nramireza@avantsante.com (N.E.R.-A.); mdjesus.loeraars@uanl.edu.mx (M.J.L.-A.); odila.saucedocr@uanl.edu.mx (O.S.-C.); aracely.garciagr@uanl.edu.mx (A.G.-G.); humberto.rodriguezrc@uanl.edu.mx (H.R.-R.)

2 Department of Surgery, School of Medicine, University of Louisville, Louisville, KY 40202, USA; rodolfo.garzamorales@utrgv.edu (R.G.-M.); igguti01@louisville.edu (J.G.G.-G.)

3 Department of Molecular Genetics, Northeast Biomedical Research Center, Mexican Institute of Social Security (IMSS), Monterrey, NL 64000, Mexico

check for updates

Citation: Martinez-Perez, A.G.; Perez-Trujillo, J.J.; Garza-Morales, R.; Ramirez-Avila, N.E.; Loera-Arias, M.J.; Gomez-Gutierrez, J.G.; Saucedo-Cardenas, O.; Garcia-Garcia, A.; Rodriguez-Rocha, H.; Montes-de-Oca-Luna, R. An Oncolytic Adenovirus Encoding SA-4-1BBL Adjuvant Fused to HPV-16 E7 Antigen Produces a Specific Antitumor Effect in a Cancer Mouse Model. Vaccines 2021, 9, 149. https://doi.org/10.3390/vaccines90 20149

Academic Editor: Takashi Imai Received: 31 December 2020

Accepted: 4 February 2021

Published: 12 February 2021

Publisher's Note: MDPI stays neutral with regard to jurisdictional claims in published maps and institutional affiliations.

Copyright: (c) 2021 by the authors. Licensee MDPI, Basel, Switzerland. This article is an open access article distributed under the terms and conditions of the Creative Commons Attribution (CC BY) license (https:// creativecommons.org/licenses/by/ $4.0 /)$.
* Correspondence: rrrmontes@gmail.com; Tel.: +52-1-81-8329-4195

+ Contributed equally.

\begin{abstract}
Human papillomaviruses (HPVs) are responsible for about $25 \%$ of cancer cases worldwide. HPV-16 E7 antigen is a tumor-associated antigen (TAA) commonly expressed in HPV-induced tumors; however, it has low immunogenicity. The interaction of 4-1BBL with its receptor induces pleiotropic effects on innate, adaptive, and regulatory immunity and, if fused to TAAs in DNA vaccines, can improve the antitumor response; however, there is low transfection and antitumor efficiency. Oncolytic virotherapy is promising for antitumor gene therapy as it can be selectively replicated in tumor cells, inducing cell lysis, and furthermore, tumor cell debris can be taken in by immune cells to potentiate antitumor responses. In this study, we expressed the immunomodulatory molecule SA-4-1BBL fused to E7 on an oncolytic adenovirus (OAd) system. In vitro infection of TC-1 tumor cells and NIH-3T3 non-tumor cells with SA/E7/4-1BBL OAd demonstrated that only tumor cells are selectively destroyed. Moreover, protein expression is targeted to the endoplasmic reticulum in both cell lines when a signal peptide (SP) is added. Finally, in an HPV-induced cancer murine model, the therapeutic oncolytic activity of OAd can be detected, and this can be improved when fused to E7 and SP.
\end{abstract}

Keywords: 4-1BBL; cancer vaccines; oncolytic virus; HPV-16 antigen

\section{Introduction}

Cancer ranks among the leading causes of mortality with approximately 8 million deaths worldwide registered in 2015 [1], predominately in low and medium socioeconomic countries. Around $25 \%$ of all cancer cases are caused by oncogenic viral infections such as human papillomavirus (HPV) 16 and 18 serotypes [2].

Current treatments are surgery, radiation therapy, and chemotherapy, resulting in efficient tumor clearance. Unfortunately, these strategies lead to adverse effects that affect the patient's quality of life, a high tumor recurrence rate, and development of resistance to chemotherapy. Thus, new therapeutic approaches have been explored. Gene therapy has been used as a vaccine technology that employs naked DNA or vectors (viral and non-viral) to express modified recombinant antigens and immunostimulant molecules to elicit a specific immune response capable of eliminating tumor cells [3]. 
HPV-16 E7 antigen is an ideal tumor-associated antigen (TAA) that has been extensively studied in preclinical vaccine research models [4]. Apart from the MHC-TCR interaction during antigen presentation, it is crucial that the binding interaction of immunostimulatory co-receptors is also present; otherwise, poor or no activation of the cell immune response is obtained. Among the immunostimulant molecules, 4-1BBL is a ligand that is expressed in several antigen-presenting cells (APCs), such as B lymphocytes, macrophages, and dendritic cells, as well as in activated T cells [5]. 4-1BBL interacts with its high-affinity 4-1BB receptor, which is overexpressed on $\mathrm{T}$ cells that have been activated by APCs or co-stimulatory agonists, and it can also be found on $\mathrm{CD} 11 \mathrm{c}+$ dendritic cells. Among the $\mathrm{T}$ cell subsets are the CD4+, CD8+, NK, NKT, and CD4+ CD25+ regulatory cells (Treg) [6], and such an interaction induces T-cell clonal expansion, survival, and the establishment of long-term immune memory $[7,8]$.

Several reports have demonstrated that specific antitumor immune responses can be elicited using naked DNA vaccines encoding 4-1BBL in conjunction with TAAs [9-11]. These types of vaccines are cheap to produce, easy to construct, and have a long shelf life, plus they can be quickly manufactured for preclinical trials. However, there are some limitations, such as a local administration route that only transfects adjacent cells and a low transfection rate, resulting in the need for multiple immunizations to elicit an effective antitumor response $[12,13]$. The development of vaccines for HPV has been widely studied due to the clinical interest for population health and because it is a classic model of a virusinduced tumor that can be developed in preclinical models under laboratory conditions for the study of specific antigen responses. This has allowed the development and commercial distribution of Gardasil and Cervarix vaccines, which are virus-like particles (VLP) used as prophylactic vaccines in teenagers, principally in order to prevent infection with HPV 16 and 18 serotypes and to reduce the odds of developing HPV-associated tumors [14]. Nevertheless, it is still necessary to develop therapeutic vaccines to counter active tumor growth and to propose new strategies for TAA vaccine designs able to elicit specific antitumor responses.

Adenoviruses are one of the most efficient in vivo gene delivery systems due to their infective capacity, allowing transfection and gene expression on adjacent and distant cells after local administration [15]. Replication-defective adenovirus vectors hold gene deletions essential for viral replication (E1a and E1b), allowing them to be safe for clinical use, and these modifications are generated through homologous recombination in cells that express the E1 gene, such as HEK-293. They were initially used for their immunogenic properties for delivering genes directly to tumor cells, inducing an antitumor immune response $[16,17]$. Oncolytic adenoviruses possess the ability to selectively replicate in tumor cells, inducing cell lysis. Furthermore, tumor cell debris can be phagocyted and processed by APCs, which can potentiate the antigen-specific immune response that normally is obtained with conventional adenoviruses [18]. Therefore, oncolytic adenoviruses are particularly attractive for antitumor gene therapy.

Herein, in this study, we report the design and characterization of an oncolytic adenovirus expressing the SP/SA/E7/4-1BBL fusion gene cloned in an oncolytic adenovirus system to generate more efficient and selectively antitumor gene therapy.

\section{Materials and Methods}

\subsection{Adenoviruses}

The oncolytic adenovirus (OAd) used in this study was synthesized by O.D.260 Inc. (Boise, ID, USA). This OAd has a 24-bp deletion in the E1A conserved region 2 (CR2), a 1222-bp-long BglII-MfeI deletion in the E3 region, in which the E3 ADP, RID $\alpha, \operatorname{RID} \beta$, and 14.7K genes are preserved, a hybrid Ad5/3 fiber, and a CMV-(SP)-SA-E7-4-1BBL-SV40 pA expression cassette inserted between the fiber gene and the E4 region. 


\subsection{DNA Constructs}

The SP-SA-E7-4-1BBL sequence, including codon optimization and restriction sites, was designed by our laboratory team, as described previously [9], and was synthesized by GenScript (Piscataway, NJ, USA).

\subsection{Cell Lines}

The human embryonic kidney cell line (HEK293) (\# CRL-1573) used for adenovirus propagation was grown in Dulbecco's modified Eagle's medium (DMEM) (\# 10-013-CV) and supplemented with 10\% fetal bovine serum (FBS). TC-1 cancer cell line (\# CRL-2785, discontinued) is derived from C57BL/6 murine lung epithelial cells that have been cotransformed with HPV16 E6/E7 and c-Ha-Ras-oncogenes. TC-1 cells were grown in RPMI1640 media (\# 10-040-CV) and supplemented with 5\% FBS (\# A31606, Thermo Scientific, Waltham, MA, USA) and $400 \mathrm{ug} / \mathrm{mL}$ G418 (A1720, Sigma Aldrich, St. Louis, MO, USA). Meanwhile, the 3T3 cell line derived from spontaneously immortalized murine embryonic fibroblasts (\# CRL-1658) was grown in DMEM (\# 10-013-CV) and supplemented with 10\% newborn calf serum (NBCS) (\#16010159, Thermo Scientific). All cell lines were purchased from the American Type Culture Collection (ATCC) (Manassas, VA, USA) and maintained at $37^{\circ} \mathrm{C}$ in a $5 \% \mathrm{CO}_{2}$ atmosphere.

\subsection{Mice}

C57BL/ 6 mice were acquired from Circulo ADN (Mexico City, Mexico). They were acclimatized for 5-7 days after their arrival and remained in our barrier animal facility at the School of Medicine, Autonomous University of Nuevo Leon, under cycles of 12-h light/12-h dark cycle, with ad libitum access to food and water in transparent cages with sawdust at a temperature of $25-28{ }^{\circ} \mathrm{C}$. The evaluation was done every other day to determine their health status, as well as changing bedding, food, and water every third day. All animal procedures were performed following institutional guidelines and the principles outlined in the National Institutes of Health Guide for the Care and Use of Laboratory Animals (NIH Publications No. 8023, revised 1978). This study was analyzed and approved by the Ethics Committee of the School of Medicine, Autonomous University of Nuevo Leon (Monterrey, NL, Mexico) (protocol No. HT18-00002).

\subsection{In Vivo Therapeutic Vaccinations}

Groups of seven mice received $5 \times 10^{4} \mathrm{TC}-1$ cells in $100 \mu \mathrm{L}$ of phosphate-buffered saline (PBS) 1X in the right flank by subcutaneous injection. Two weeks after the tumor implant, the mice were randomly separated into five groups to receive the corresponding treatment. The three groups of mice that were immunized with the different OAds were injected intratumorally with $2.5 \times 10^{8} \mathrm{UI}$ in $20 \mu \mathrm{L}$ of PBS 1X two times, one per week. The group that was treated with the DNA construct received $1 \mu \mathrm{g}$ of DNA using the gene gun system on the shaved abdominal skin, with 1 immunization weekly for two weeks. The last group was treated intratumorally with $20 \mu \mathrm{L}$ of PBS $1 \mathrm{X}$ as a negative control two times, one per week. Tumor progression was evaluated by measuring the tumor diameter three times per week using a digital caliper, and tumor volume was calculated by using the following formula: tumor volume $=\left(\right.$ tumor minor diameter $\left.{ }^{2}\right) \times($ tumor major diameter) $/ 2$. For survival analysis, all tumor-bearing mice were euthanized when tumors reached $1800 \mathrm{~mm}^{3}$ in tumor volume or earlier if ulceration was present or mice showed signs of discomfort.

\subsection{Immunofluorescence}

Cells $\left(5 \times 10^{4}\right)$ were seeded overnight over $8 \mathrm{~mm}$ coverslips in a 24 -well plate. The next day, the cells were infected with a multiplicity of infection (MOI) of 40 (for HEK-293) or 400 (for TC-1 and 3T3). After $16 \mathrm{~h}$ post-infection, cells were washed with cold PBS 1X, fixed with cold methanol for $10 \mathrm{~min}$ at $-20^{\circ} \mathrm{C}$, and permeabilized with cold acetone for $30 \mathrm{~s}$. Cells were washed with PBS $1 \mathrm{x}$, blocked with $3 \%$ horse serum for $1 \mathrm{~h}$ at $4{ }^{\circ} \mathrm{C}$, and incubated with 
a mix of anti-E7 monoclonal antibody (NM2) (Cat\# sc-65711, Santa Cruz Biotechnology, Dallas, TX, USA) and anti-calnexin (H-70) (Cat\# sc-11397, Santa Cruz Biotechnology) at a 1:500 dilution for $12 \mathrm{~h}$ at $4{ }^{\circ} \mathrm{C}$. Next, cells were washed again and incubated for $2 \mathrm{~h}$ with goat anti-mouse IgG (H + L) CF594 and goat anti-rabbit CF488A IgG (H + L) (Santa Cruz Biotechnology). Coverslips were washed and mounted with Vectashield antifade mounting medium with 4',6-diamidino-2-phenylindole (DAPI) (Vector Laboratories, Burlingame, CA, USA).

\subsection{Western Blot Analysis}

HEK-293 cells $\left(5 \times 10^{5}\right)$ were seeded overnight in a 6-well plate. Next, they were infected with different MOIs from 5 to 40 , incubated for $48 \mathrm{~h}$, and processed as follows. Cells were harvested for the radioimmunoprecipitation assay buffer (RIPA buffer) lysis protocol. Cell lysates were quantified with the Pierce BCA protein kit (Thermo Scientific). A total of $25 \mu \mathrm{g}$ of total proteins were electrophoresed on 10\% SDS-polyacrylamide gels and transferred to PVDF membranes (GE Healthcare Life Sciences, Pittsburgh, PA, USA). Membranes were blocked with $10 \%$ skim-milk and then incubated with mouse anti-E7 monoclonal antibody (NM2) (sc-65711, Santa Cruz Biotechnology) and mouse anti- $\beta$-actin monoclonal antibody (A2228, Sigma-Aldrich). All washing steps were performed using TBS-Tween 1x. Next, membranes were incubated with secondary antibody anti-mouse HRP (1:5000, Bio-Rad Laboratories Inc., 170-6516) and developed with Supersignal West Pico Chemiluminescent Substrate kit (Thermo Fisher Scientific Inc., Waltham, MA, USA). For reproved incubations, membranes were stripped with stripping buffer $1 \times \mathrm{pH} 2.2$ and incubated in $10 \%$ skim-milk.

\subsection{Viral Titration}

To estimate the viral particle number present in the crude extracts, we performed the MOI calculation protocol as reported in [19]. In a 6-well plate with $1 \times 10^{6} \mathrm{HEK}-293$ cells/well, the medium was completely removed and $500 \mu \mathrm{L}$ of fresh medium was added, followed by the addition of $25,50,100,150$, and $200 \mu \mathrm{L}$ of the crude extract to be tested. Cells were incubated for $3 \mathrm{~h}$ at $37^{\circ} \mathrm{C}, 5 \% \mathrm{CO}_{2}$; subsequently, $1.5 \mathrm{~mL}$ of fresh medium was added to each well and incubated for $72 \mathrm{~h}$. After that, cells were visually analyzed for cytopathic effect (CPE), where the minimum extract crude volume that produced CPE was considered as an MOI of 20. Uninfected cells were used as a negative control for CPE.

\subsection{MTT and Violet Crystal Assays for Cell Viability}

For MTT assays, $5 \times 10^{3}$ cells/well were seeded in a 96-well plate in $200 \mu \mathrm{L}$ of medium and incubated overnight for cell adherence. Next, $100 \mu \mathrm{L}$ of medium/well was replaced with $200 \mu \mathrm{L}$ of fresh media containing the indicated MOI and incubated for $72 \mathrm{~h}$ at $37^{\circ} \mathrm{C}$. Then, $30 \mu \mathrm{L}$ of MTT reagent $(5 \mathrm{mg} / \mathrm{mL})$ was added to each well and incubated until precipitate formation was observed $(\sim 2 \mathrm{~h})$. Finally, the medium was removed, $100 \mu \mathrm{L}$ of DMSO was added for crystal solubilization, and the absorbance was read at $595 \mathrm{~nm}$ on the iMark Plate Reader (Bio-Rad).

For the violet crystal assay, $5 \times 10^{4}$ cells/well were seeded in a 24-well plate and incubated overnight for cell adherence. Next, the medium was replenished with $2 \mathrm{~mL}$ of fresh media containing the indicated MOI and incubated for $72 \mathrm{~h}$ at $37^{\circ} \mathrm{C}$. The medium was removed, and $200 \mu \mathrm{L}$ of $1 \%$ crystal violet-methanol was added and incubated for 20 min at RT. Then, the dye was removed and rinsed $4-5$ times with ddH2O, and the plate was allowed to dry completely. Subsequently, $400 \mu \mathrm{L}$ of methanol was added and left to incubate for $20 \mathrm{~min}$ at RT, stirring occasionally. Finally, the absorbance was read at $595 \mathrm{~nm}$ on the iMark Plate Reader (Bio-Rad). Uninfected cells were used as the negative control and considered as $100 \%$ cell viability. 


\subsection{Statistical Analysis}

One-way ANOVA, followed by Dunnett's multiple comparisons test, was performed to determine differences in cell viability across different treatments in the violet crystal assay. Two-way ANOVA, followed by Tukey's multiple comparisons test, was performed to determine differences in cell viability across different treatments in the MTT assay. Both were performed using GraphPad Prism software version 6 (GraphPad Software, La Jolla, CA, USA). Differences with $p \leq 0.05$ were considered significant (ns $p>0.05,{ }^{*} p \leq 0.05$, $\left.{ }^{* *} p \leq 0.01,{ }^{* * *} p \leq 0.001,{ }^{* * * *} p \leq 0.0001\right)$. All assays were performed at least twice, each one with triplicate data.

\section{Results}

\subsection{SP/SA/E7/4-1BBL Protein Expression through Oncolytic Adenovirus Infection}

In order to demonstrate whether the oncolytic adenovirus (OAd) expresses the SP/SA/E7/4-1BBL recombinant protein, HEK-293 cells were infected with the OAd at different multiplicity of infection (MOI) concentrations. After $72 \mathrm{~h}$, cell lysates were analyzed by Western blot. Western blot analysis revealed a $55 \mathrm{kDa}$ signal when using a monoclonal antibody against the E7 antigen, which corresponds to the expected molecular weight of the SP/SA/E7/4-1BBL recombinant protein (Figure 1a). Moreover, a dose-dependent increase in signal intensity was visualized with higher MOI concentrations, and in order to estimate the fold increase between each MOI concentration, a densitometric analysis was performed using the coefficient between SP/SA/E7/4-1BBL and actin (Figure 1b). The results show that at an MOI concentration of 5-20, there was no significant difference; therefore, it was used at an MOI of 40, which represents a 2-fold increase in the expression of the recombinant protein compared to actin. (Figures S1 and S2)

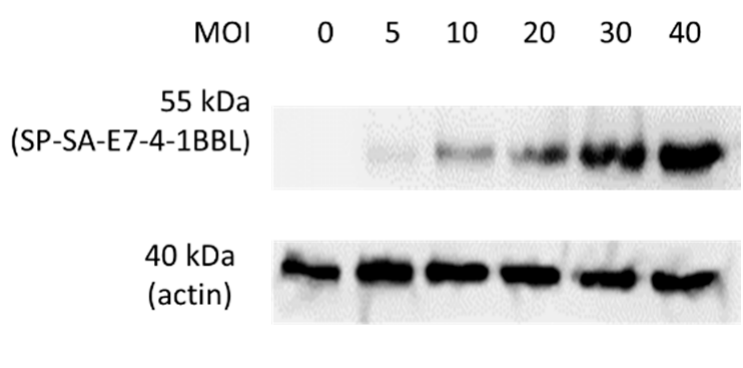

(a)

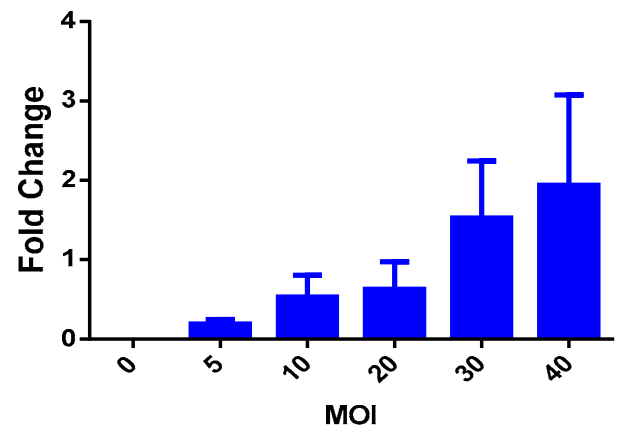

(b)

Figure 1. Detection of SP/SA/E7/4-1BBL protein expression in HEK-293 cells. (a) Fifty-five kDa bands corresponding to the protein of interest at MOI concentrations of $0,5,10,20,30$, and 40; normalized results with actin as an endogenous control. (b) Densitometry graph where greater expression of SP/SA/E7/4-1BBL protein is observed in a dose-dependent manner, relative to the expression of actin. MOI, multiplicity of infection.

\subsubsection{Subcellular Localization of SP/SA/E7/4-1BBL Recombinant Protein}

Since the SP/SA/E7/4-1BBL protein contains the signal peptide (SP) from human calreticulin (CRT), the recombinant protein is expected to be targeted to the endoplasmic reticulum (ER). To demonstrate this, an immunofluorescence assay was performed on infected HEK-293 (Figure 2a), TC-1 (Figure 2b), and NIH/3T3 (Figure 2c) cells. Once the cytopathic effect was observed, immunofluorescence was performed using antibodies against E7 and calnexin. The results reveal that the E7 signal (red) shows a perinuclear pattern that overlaps with the calnexin signal (green). In conclusion, we observed colocalization of both signals, demonstrating that our protein of interest is located in the ER. 


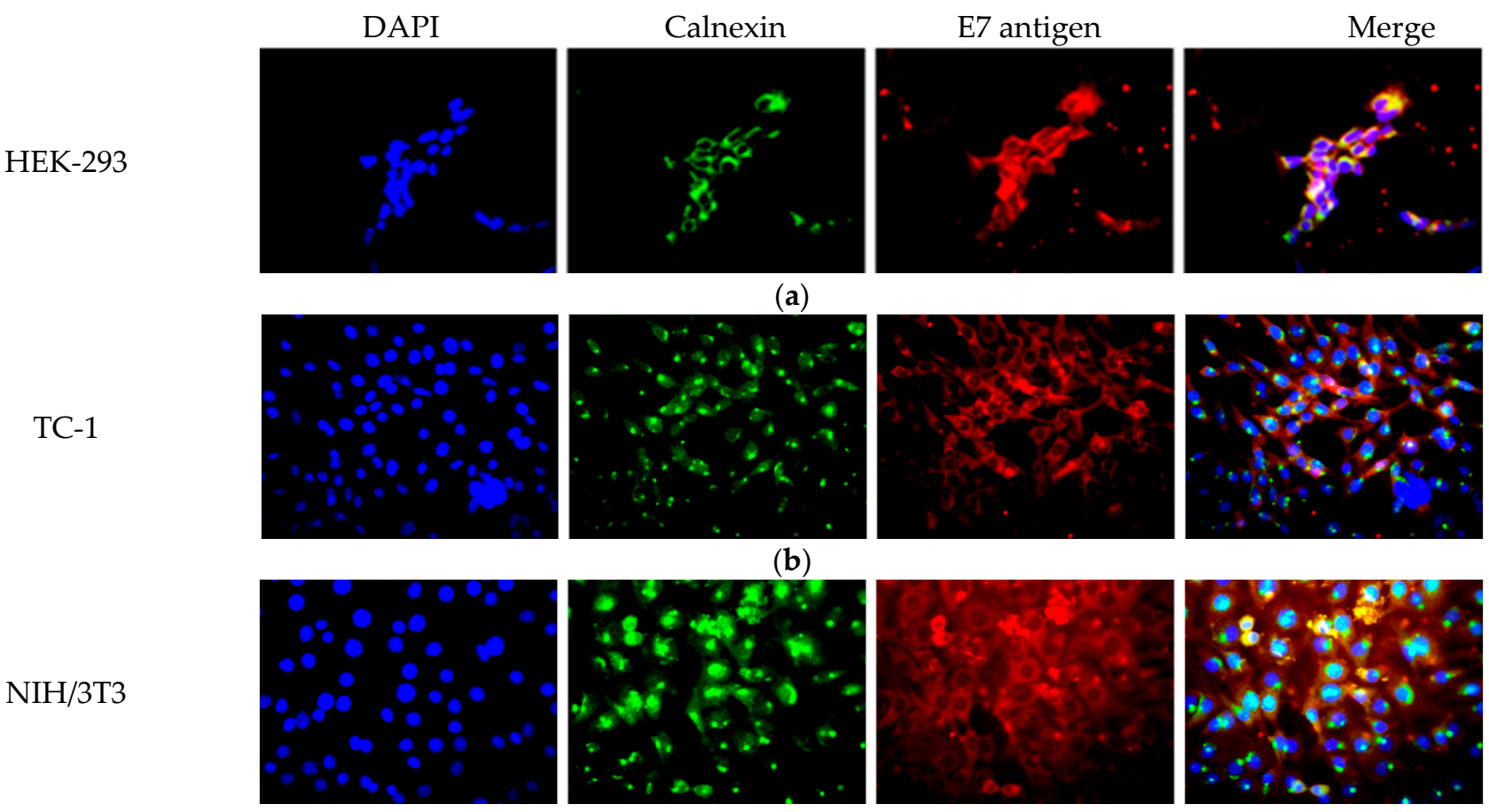

(c)

Figure 2. Subcellular localization of SP/SA/E7/4-1BBL recombinant protein in (a) HEK-293, (b) TC-1, and (c) NIH/3T3 cell lines. Blue channel DAPI signal for the nucleus, red channel signal for E7 antigen, green channel signal for calnexin; merge (yellow stain) shows co-localization of signals for E7 and calnexin. DAPI, 4',6-diamidino-2-phenylindole.

\subsubsection{The Recombinant Oncolytic Adenovirus Displays Antitumor Activity In Vitro}

To prove that oncolytic adenovirus (OAd) expressing SP/SA/E7/4-1BBL can lyse tumor cells, we proposed infecting the tumor TC-1 cell line at different MOI concentrations for $72 \mathrm{~h}$. It has been reported that some mouse cells are semi-permissive to OAd infection; therefore, we opted to increase the MOI concentration to 10- to 100-fold [20,21]. Cell viability was observed as detachment and decreased cell density, and the cytopathic effect was evaluated with the crystal violet assay (Figure 3). The results show that cell viability decreased in a dose-dependent manner: $97 \%$ at an MOI of 500, 94\% at an MOI of 1000, 44\% at an MOI of 2500, and $30 \%$ at an MOI of 5000. Moreover, the last two MOI concentrations were statistically significant $(p<0.001)$, thus confirming its ability to lyse tumor cells.

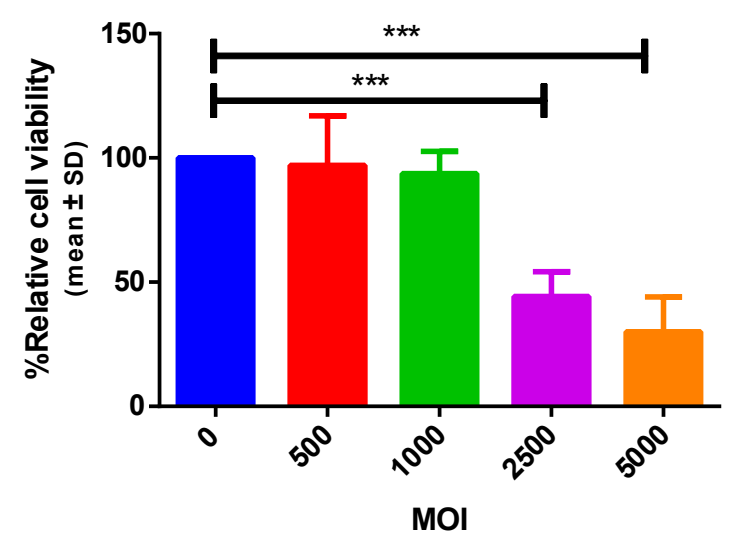

Figure 3. In vitro antitumor effect of oncolytic adenovirus expressing SP/SA/E7/4-1BBL. Cell viability percentage of TC-1 cells was measured by crystal violet assay after infection with adenoviruses at different MOIs, which decreases while MOI increases, compared to infection-free control. ${ }^{* * *}(p<0.001)$. 


\subsubsection{The Cell Killing Effect of OAd Is Specific to Tumor Cells}

Next, in order to demonstrate that the oncolytic effect of OAd expressing SP/SA/E7/41BBL is specific to tumor cells, TC-1 and NIH/3T3 cells were infected with OAd at different MOI concentrations for $72 \mathrm{~h}$. Light microscopy revealed detachment and decreased cell density in infected TC- 1 cells (cell count 58\% at MOI 250, 36\% at MOI 2500, and $29 \%$ at MOI 5000 with respect to cells without infection) (Figure 4a). This was in contrast to the non-tumor cell line NIH/3T3, which was unaffected by OAd (cell count 105\% at MOI $250,104 \%$ at MOI 2500 , and $133 \%$ at MOI 5000 with respect to cells without infection), corroborated by quantification using Image J Cell Counter (Figure $4 \mathrm{~b}$ ). To quantify this effect, an MTT assay was performed to evaluate cell viability. At $72 \mathrm{~h}$ post-infection, TC-1 cells infected with OAd at MOI concentrations of 2500 and 5000 displayed a $43 \%(p<0.05)$ and $67 \%(p<0.01)$ decrease in cell viability, respectively, when compared to OAd-infected $\mathrm{NIH} / 3 \mathrm{~T} 3$ cells at the same MOI concentrations (Figure 5).

$\mathrm{MOI}$

0

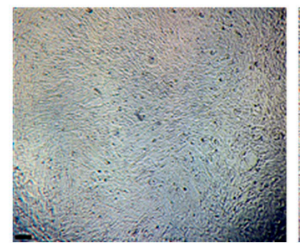

TC-1

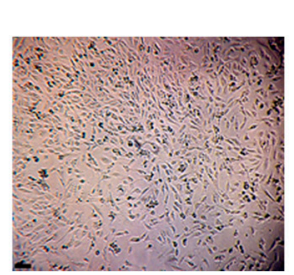

$\mathrm{NIH} /$

3T3
250

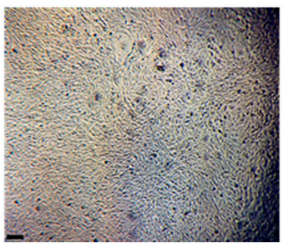

(a)

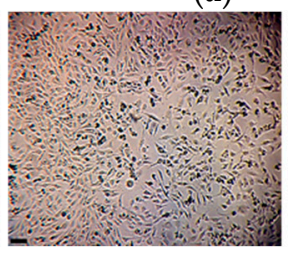

(b)
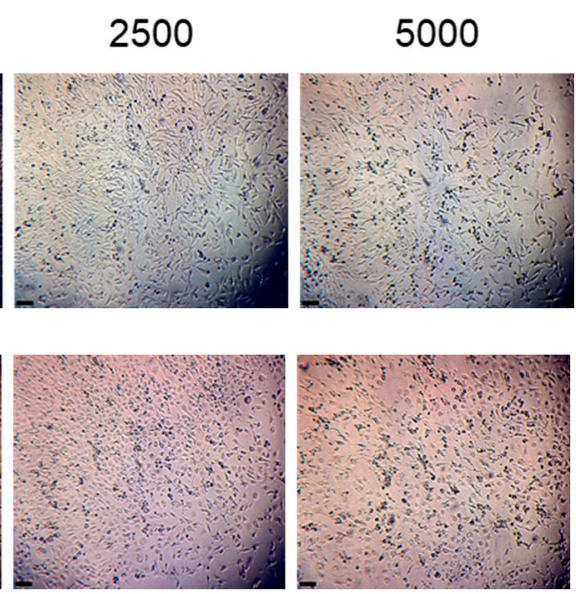

5000

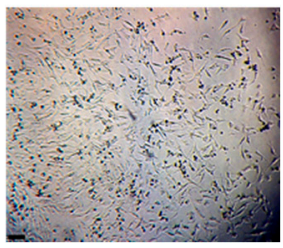

Figure 4. Specific oncolytic effect against tumoral cells. Evaluation of cellular density by light-field microscopy of TC-1 (a) and NIH/3T3 (b) cells after infection with oncolytic adenoviruses. Both cell lines were infected with different MOIs and incubated for $72 \mathrm{~h}$. The TC-1 tumor cell line displays detachment and a decrease in cell density as MOI increases; nevertheless, the NIH/3T3 non-tumor cell line was unaltered. $1=0$ MOI, $2=250$ MOI, $3=2500$ MOI, $4=5000$ MOI. Scale bars $100 \mu \mathrm{m}$.

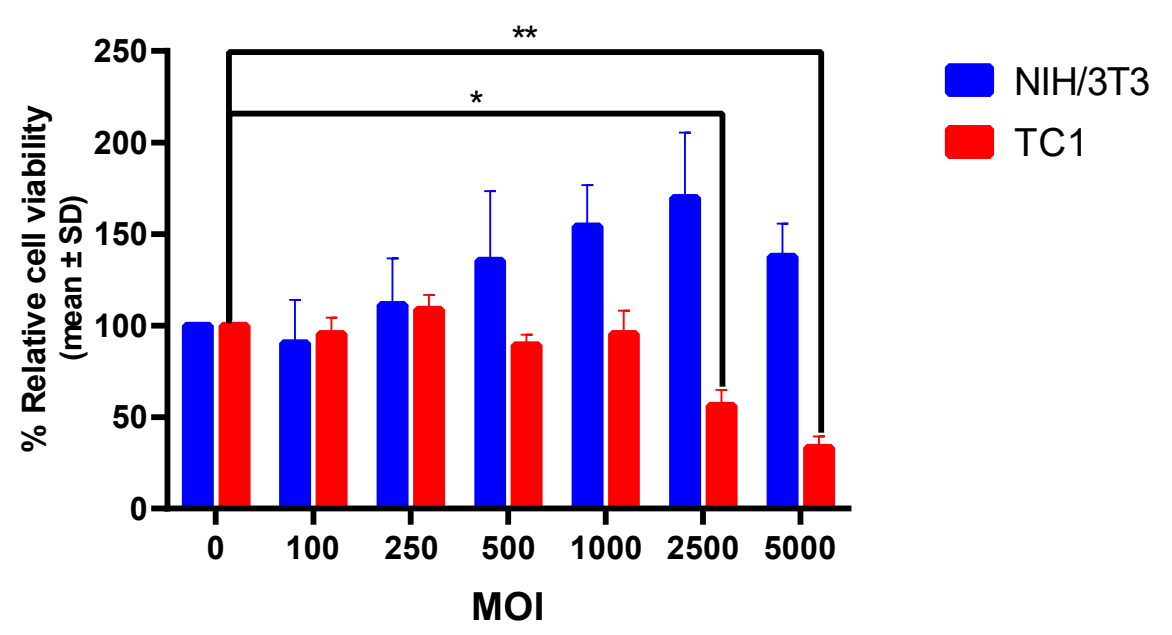

Figure 5. Cell viability percentage graph after $72 \mathrm{~h}$ post-infection with recombinant oncolytic adenoviruses. The TC-1 cell line displayed $43 \%$ mortality at an MOI of $2500 *(p<0.05)$ and $67 \%$ at an MOI of $5000^{* *}(p<0.01)$, while the non-tumor NIH/3T3 cell line exhibited no significant changes. 


\subsubsection{The Recombinant Oncolytic Adenovirus Exhibits Antitumor Efficacy In Vivo}

Next, to corroborate the oncolytic in vitro effect previously observed, we performed a therapeutic antitumor assay in a TC-1 mouse cancer model. Six- to 8-week-old C57BL/6 female mice were challenged with $5 \times 10^{4} \mathrm{TC}-1$ cells injected in the right flank by subcutaneous injection. At 14 days after the tumor challenge (average tumor volume at $198.1 \mathrm{~mm}^{3}$ \pm SEM 26.4), mice were intratumorally injected with OAd expressing SP-SA-E7-4-1BBL, SA-E7-4-1BBL, or SP-SA-4-1BBL at a concentration of $2.5 \times 10^{8}$ UI. As a positive reference control, one group of mice was administered $1 \mu \mathrm{g}$ of DNA constructs on shaved abdominal skin through the gene gun system, while another group of mice was injected with PBS 1X as a negative control. All groups received a weekly dose for two weeks. Tumor growth was monitored three times per week. By day 10 after the first treatment dose, we found tumor growth suppression in mice that were immunized with SP-SA-E7-4-1BBL (OAd) $(p \leq 0.0001)$ and SP-SA-E7-4-1BBL (DNA construct used as a positive reference control) $(p \leq 0.001)$, compared with the negative control (Figure 6a). Moreover, at the same time, the negative control and SP-SA-4-1BBL (OAd) mice groups reached tumor volume endpoint criteria, while the rest of the groups maintained $100 \%$ survival (Figure 6b). From this point to the end of the study (week 4 ), there was no statistically significant difference observed between the three remaining groups $(p=0.4910)$. Overall, these results demonstrate that the oncolytic adenovirus expressing SP-SA-E7-4-1BBL and SA-E7-4-1BBL is as effective in delaying tumor progression as the DNA vaccine expressing SP-SA-E7-4-1BBL.

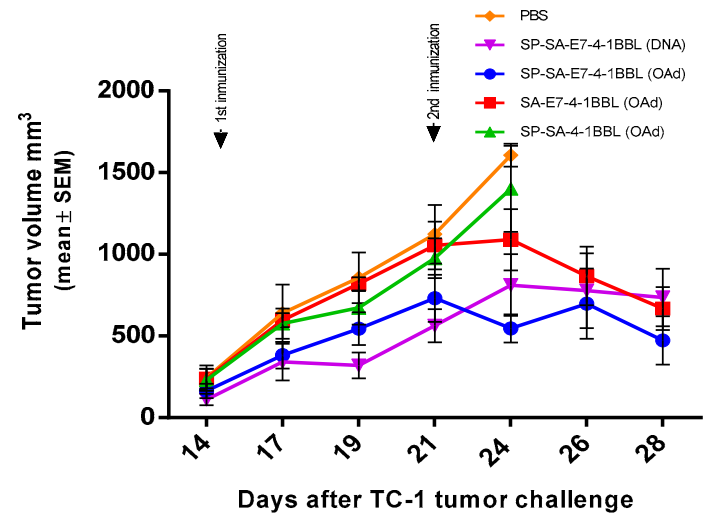

(a)

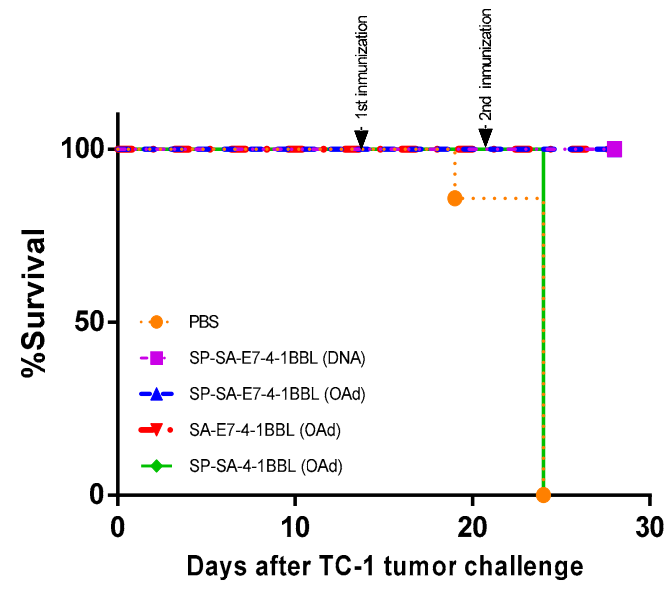

(b)

Figure 6. In vivo therapeutic antitumor effect of oncolytic adenovirus. (a) Tumor volume was measured after the first administration of oncolytic adenovirus DNA or PBS at 14 days after tumor challenge with $5 \times 10^{4}$ TC- 1 cells in the right flank by subcutaneous injection. Groups $(n=7)$ of 6 - to 8-week-old C57BL/6 mice were injected intratumorally with $2.5 \times 10^{8} \mathrm{UI}$ of oncolytic adenovirus two times (one per week). The DNA construct was administrated on shaved abdominal skin with $1 \mu \mathrm{g}$ of DNA using a gene gun system. PBS was used as a negative control. Tumor volumes are represented by mean \pm SEM. Mice were euthanized when the tumor volume was higher than $1800 \mathrm{~mm}^{3}$. (b) Survival graph after TC-1 tumor challenge. Two-way ANOVA and post-hoc Tukey's tests were performed.

\section{Discussion}

To guarantee an efficient infection with oncolytic adenovirus, it is important to consider the mechanism of cellular internalization of the virus and the species of origin of the cell lines used in the assays. The coxsackie-adenovirus (CAR) receptor is the primary receptor used by the OAd to attach to the cell surface, followed by an interaction with cellular integrins. Therefore, in cells that have low or no CAR expression, the internalization pathway depends exclusively on the integrins [22]. Human cells express CAR, so they can be infected with a low MOI. On the contrary, murine cells have a low expression of this receptor, and therefore, elevated MOI concentrations should be used to assure their 
transduction. In the present study, TC-1 and NIH/3T3 murine cell lines had to be infected with an MOI of up to 5000 to achieve a cytopathic effect.

All adenovirus-based vectors are derived from the human adenovirus serotype 5, which makes these viruses unable to produce progeny in murine cells [23,24]. Nevertheless, human adenoviruses in murine cells can produce the necessary viral proteins by regulating the transcription-translation machinery of infected cells, even though OAds are not able to produce their progeny efficiently [25]. This was demonstrated by the ability of OAds to direct the expression of the SP/SA/E7/4-1BBL protein in tumor and normal murine cells.

Since the SP/SA/E7/4-1BBL recombinant protein contains a signal peptide (SP) from human calreticulin (CRT), we demonstrated its localization in the ER lumen. Previously, we have demonstrated that adding a signal peptide (SP) and ER-retaining signal (KDEL) to the E7 antigen confers a more potent antitumor effect [26,27]. However, in this case, our interest was for this protein to be sent only to the secretory pathway without being held in the ER. Therefore, only the SP was added, and this would also help for the correct protein folding for 4-1BBL.

Recently, we proved that the SP-SA-E7-4-1BBL DNA vaccine exhibited outstanding therapeutic and prophylactic effects against HPV-16 E7-expressing TC-1 tumors [9]. DNA vaccines offer several advantages, such as easy use at low cost and especially their ability to stimulate cellular and humoral responses. Nevertheless, this effect has been limited to preclinical models [28]. Replication-competent adenoviruses have been broadly used in cancer gene therapy, and they are designed to replicate preferentially in tumor cells and destroy them through the natural lytic process of viral replication [29]. Therefore, we decided to use a combination of these two mechanisms: the expression of a transgene that has previously demonstrated an antitumor effect and the specific lysis of tumor cells by oncolytic adenoviruses.

In this study, we show that oncolytic adenovirus has a cell killing effect on TC-1 tumor cells. It has been reported that even in the absence of viral progeny production, excessive production of viral proteins can result in the death of infected tumor murine cells, primarily by the activation of autophagy, although it is capable of activating other types of cell death [30-32].

After we showed that OAd is capable of infecting NIH/3T3 non-tumor cells and expressing the SP/SA/E7/4-1BBL protein, we evaluated whether cell viability was affected. Therefore, we performed a viability assay on both murine cell lines. The MTT assay results revealed that the non-tumor cell line had no decrease in its viability, and instead, that there was an increase in metabolic viability in infected cells compared to the infection-free control.

To survive and replicate in cells, viruses must take control of the various cellular organelles involved in defense and immune processes. Once inside the host cell, they modulate cell signalization pathways and organelles, including mitochondria, and use them for their own survival [33]. As has been reported, increased metabolic viability may be due to hyperactive mitochondria or an increase in mitochondrial mass, since the conversion of MTT into formazan occurs mainly in the mitochondria [34]. Therefore, a non-tumor cell line can cause an increment in mitochondrial activity during Ad infection, resulting in a false cell proliferation signal; otherwise, a tumor line would be affected and eventually lysed by OAd, causing a reduction of formazan formation.

All together, these results show that the oncolytic adenovirus used in this study can express the protein SP/SA/E7/4-1BBL, which is targeted to the ER lumen. Although this expression occurs in both tumor and non-tumor cells, the cell killing effect is restricted to tumor cells. To corroborate this specific antitumor effect in vivo, we demonstrate in this study that the administration of OAd encoding 4-1BBL fused to E7 antigen in mice with established tumors resulted in the suppression of tumor growth, as well as in $100 \%$ survival regarding the reference control. When we compare such effects with the administration of the gene construct as a DNA vaccine, we observed that the antitumor effect is equivalent. Therefore, it was possible to improve delivery and specificity without compromising the 
previously demonstrated antitumor effect [9]. Further studies should analyze the safety and biodistribution of recombinant adenovirus, as well as correlate the mechanisms involved in the antitumor effect. It should be noted that although our study focused on the E7 antigen and an HPV-induced mouse cancer model, this strategy can be translated to a variety of tumor-associated antigens for cancer gene therapy.

\section{Conclusions}

In the present study, we report the design of an oncolytic adenovirus expressing the $\mathrm{SP} / \mathrm{SA} / \mathrm{E} 7 / 4-1 \mathrm{BBL}$ fusion gene, which is capable of infecting murine cancer and normal cells, and the expressed protein was able to be targeted to the endoplasmic reticulum. Most importantly, OAd induced a cell killing effect that is specific to cancer cells. Moreover, OAd treatment induced a potent antitumor effect in a mouse TC-1 cancer model.

Supplementary Materials: The following are available online at https:/ /www.mdpi.com/2076-393 X/9/2/149/s1, Figure S1: Original Figure 1 ACTIN, Figure S2: Original Figure 1 SP-SA-E7-4-1BBL.

Author Contributions: A.G.M.-P. and J.J.P.-T. wrote the paper. A.G.M.-P., J.J.P.-T., and N.E.R.-A. performed the experiments; R.M.-d.-O.-L., O.S.-C., J.G.G.-G., and R.G.-M. conceived and designed the experiments and edited the manuscript; R.M.-d.-O.-L., J.G.G.-G., A.G.-G., H.R.-R., O.S.-C., and M.J.L.A. analyzed the data; A.G.M.-P., J.J.P.-T., R.G.-M., O.S.-C., and R.M.-d.-O.-L. revised the manuscript. All authors have read and agreed to the published version of the manuscript.

Funding: This study received funding through a grant from the National Council for Science and Technology (CONACYT, grant No. 255725 (R.M.-d.-O.-L.) and in part by Jewish Heritage Fund for Excellence Research Enhancement Grant Program at the University of Louisville, School of Medicine (award \# OGMN190574M, JGG). A-G.M-P. and N.E.R.-A. were recipients of scholarships from CONACYT.

Institutional Review Board Statement: The study was conducted according to the guidelines of the Declaration of Helsinki and approved by the Ethics Committee of the School of Medicine, Autonomous University of Nuevo Leon (Monterrey, NL, Mexico) (protocol No. HT18-00002 approved in December 2018).

Informed Consent Statement: Not applicable.

Conflicts of Interest: The authors declare no conflict of interest.

\section{References}

1. Cáncer. Available online: https://www.who.int/es/news-room/fact-sheets/detail/cancer (accessed on 6 January 2020).

2. Plummer, M.; de Martel, C.; Vignat, J.; Ferlay, J.; Bray, F.; Franceschi, S. Global burden of cancers attribufigure to infections in 2012: A synthetic analysis. Lancet Glob. Health 2016, 4, e609-e616. [CrossRef]

3. Khan, K.H. DNA vaccines: Roles against diseases. Germs 2013, 3, 26-35. [CrossRef]

4. Lin, K.-Y.; Guarnieri, F.G.; Staveley-O'Carroll, K.F.; Levitsky, H.I.; August, J.T.; Pardoll, D.M.; Wu, T.-C. Treatment of Established Tumors with a Novel Vaccine That Enhances Major Histocompatibility Class II Presentation of Tumor Antigen. Cancer Res. 1996, 56, 21-26. [PubMed]

5. Li, S.-Y.; Liu, Y. Immunotherapy of melanoma with the immune costimulatory monoclonal antibodies targeting CD137. Clin. Pharmacol. Adv. Appl. 2013, 5, 47-53. [CrossRef] [PubMed]

6. Vinay, D.S.; Kwon, B.S. Immunotherapy of cancer with 4-1BB. Mol. Cancer Ther. 2012, 11, 1062-1070. [CrossRef] [PubMed]

7. Helmy, K.Y.; Patel, S.A.; Nahas, G.R.; Rameshwar, P. Cancer immunotherapy: Accomplishments to date and future promise. Ther. Deliv. 2013, 4, 1307-1320. [CrossRef]

8. Lee, H.-W.; Park, S.-J.; Choi, B.K.; Kim, H.H.; Nam, K.-O.; Kwon, B.S. 4-1BB promotes the survival of CD8+ T lymphocytes by increasing expression of Bcl-xL and Bfl-1. J. Immunol. 2002, 169, 4882-4888. [CrossRef]

9. Garza-Morales, R.; Perez-Trujillo, J.J.; Martinez-Jaramillo, E.; Saucedo-Cardenas, O.; Loera-Arias, M.J.; Garcia-Garcia, A.; Rodriguez-Rocha, H.; Yolcu, E.; Shirwan, H.; Gomez-Gutierrez, J.G.; et al. A DNA Vaccine Encoding SA-4-1BBL Fused to HPV-16 E7 Antigen Has Prophylactic and Therapeutic Efficacy in a Cervical Cancer Mouse Model. Cancers 2019, 11, 96. [CrossRef] [PubMed]

10. Ragonnaud, E.; Andersson, A.-M.C.; Pedersen, A.E.; Laursen, H.; Holst, P.J. An adenoviral cancer vaccine co-encoding a tumor associated antigen together with secreted 4-1BBL leads to delayed tumor progression. Vaccine 2016, 34, 2147-2156. [CrossRef] [PubMed] 
11. Jin, C.; Liu, Y.; Zhu, J.; Xia, T.; Zhang, B.; Fei, Y.; Ma, B.; Ye, J.; Chen, W. Recombinant Salmonella-based CEACAM6 and 4-1BBL vaccine enhances T-cell immunity and inhibits the development of colorectal cancer in rats: In vivo effects of vaccine containing 4-1BBL and CEACAM6. Oncol. Rep. 2015, 33, 2837-2844. [CrossRef]

12. Keskin, D.B.; Anandappa, A.J.; Sun, J.; Tirosh, I.; Mathewson, N.D.; Li, S.; Oliveira, G.; Giobbie-Hurder, A.; Felt, K.; Gjini, E.; et al. Neoantigen vaccine generates intratumoral T cell responses in phase Ib glioblastoma trial. Nature 2019, 565, 234-239. [CrossRef] [PubMed]

13. Kamensek, U.; Cemazar, M.; Lampreht Tratar, U.; Ursic, K.; Sersa, G. Antitumor in situ vaccination effect of TNF $\alpha$ and IL-12 plasmid DNA electrotransfer in a murine melanoma model. Cancer Immunol. Immunother. 2018, 67, 785-795. [CrossRef] [PubMed]

14. Bruni, L.; Diaz, M.; Barrionuevo-Rosas, L.; Herrero, R.; Bray, F.; Bosch, F.X.; de Sanjosé, S.; Castellsagué, X. Global estimates of human papillomavirus vaccination coverage by region and income level: A pooled analysis. Lancet Glob. Health 2016, 4, e453-e463. [CrossRef]

15. Lee, C.S.; Bishop, E.S.; Zhang, R.; Yu, X.; Farina, E.M.; Yan, S.; Zhao, C.; Zeng, Z.; Shu, Y.; Wu, X.; et al. Adenovirus-mediated gene delivery: Potential applications for gene and cell-based therapies in the new era of personalized medicine. Genes Dis. 2017, 4, 43-63. [CrossRef] [PubMed]

16. Wu, Q.; Xia, D.; Xiang, S.C.; Xiang, J. Adenovirus-Mediated Transgene-Engineered Dendritic Cell Vaccine of Cancer. Available online: http:/ / www.eurekaselect.com/60560/article (accessed on 13 January 2020).

17. Deisseroth, A.; Tang, Y.; Zhang, L.; Akbulut, H.; Habib, N. TAA/ecdCD40L adenoviral prime-protein boost vaccine for cancer and infectious diseases. Cancer Gene Ther. 2013, 20, 65-69. [CrossRef]

18. Howells, A.; Marelli, G.; Lemoine, N.R.; Wang, Y. Oncolytic Viruses-Interaction of Virus and Tumor Cells in the Battle to Eliminate Cancer. Front. Oncol. 2017, 7, 195. [CrossRef]

19. Luo, J.; Deng, Z.-L.; Luo, X.; Tang, N.; Song, W.-X.; Chen, J.; Sharff, K.A.; Luu, H.H.; Haydon, R.C.; Kinzler, K.W.; et al. A protocol for rapid generation of recombinant adenoviruses using the AdEasy system. Nat. Protoc. 2007, 2, 1236-1247. [CrossRef]

20. Duncan, S.J.; Gordon, F.C.A.; Gregory, D.W.; McPhie, J.L.; Postlethwaite, R.; White, R.; Willcox, H.N.A. Infection of Mouse Liver by Human Adenovirus Type 5. J. Gen. Virol. 1978, 40, 45-61. [CrossRef]

21. Ganly, I.; Mautner, V.; Balmain, A. Productive Replication of Human Adenoviruses in Mouse Epidermal Cells. J. Virol. 2000, 74, 2895-2899. [CrossRef]

22. Lyle, C.; McCormick, F. Integrin $\alpha \mathrm{v} \beta 5$ is a primary receptor for adenovirus in CAR-negative cells. Virol. J. 2010, 7, 148. [CrossRef]

23. Blair, G.E.; Dixon, S.C.; Griffiths, S.A.; Zajdel, M.E. Restricted replication of human adenovirus type 5 in mouse cell lines. Virus Res. 1989, 14, 339-346. [CrossRef]

24. Jogler, C.; Hoffmann, D.; Theegarten, D.; Grunwald, T.; Überla, K.; Wildner, O. Replication Properties of Human Adenovirus In Vivo and in Cultures of Primary Cells from Different Animal Species. J. Virol. 2006, 80, 3549-3558. [CrossRef] [PubMed]

25. Kim, J.W.; Miska, J.; Young, J.S.; Rashidi, A.; Kane, J.R.; Panek, W.K.; Kanojia, D.; Han, Y.; Balyasnikova, I.V.; Lesniak, M.S. A Comparative Study of Replication-Incompetent and -Competent Adenoviral Therapy-Mediated Immune Response in a Murine Glioma Model. Mol. Ther. Oncolytics 2017, 5, 97-104. [CrossRef]

26. Perez-Trujillo, J.J.; Garza-Morales, R.; Barron-Cantu, J.A.; Figueroa-Parra, G.; Garcia-Garcia, A.; Rodriguez-Rocha, H.; GarciaJuarez, J.; Muñoz-Maldonado, G.E.; Saucedo-Cardenas, O.; Montes-De-Oca-Luna, R.; et al. DNA vaccine encoding human papillomavirus antigens flanked by a signal peptide and a KDEL sequence induces a potent therapeutic antitumor effect. Oncol. Lett. 2017, 13, 1569-1574. [CrossRef] [PubMed]

27. Loera-Arias, M.J.; Martínez-Pérez, A.G.; Barrera-Hernández, A.; Ibarra-Obregón, E.R.; González-Saldívar, G.; Martínez-Ortega, J.I.; Rosas-Taraco, A.; Villanueva-Olivo, A.; Esparza-González, S.C.; Villatoro-Hernandez, J.; et al. Targeting and retention of HPV16 E7 to the endoplasmic reticulum enhances immune tumour protection. J. Cell. Mol. Med. 2010, 14, 890-894. [CrossRef]

28. Lopes, A.; Vandermeulen, G.; Préat, V. Cancer DNA vaccines: Current preclinical and clinical developments and future perspectives. J. Exp. Clin. Cancer Res. 2019, 38, 146. [CrossRef]

29. Wold, W.S.M.; Toth, K. Adenovirus vectors for gene therapy, vaccination and cancer gene therapy. Curr. Gene Ther. 2013, 13, 421-433. [CrossRef]

30. Jiang, H.; White, E.J.; Ríos-Vicil, C.I.; Xu, J.; Gomez-Manzano, C.; Fueyo, J. Human Adenovirus Type 5 Induces Cell Lysis through Autophagy and Autophagy-Triggered Caspase Activity. J. Virol. 2011, 85, 4720-4729. [CrossRef]

31. Klein, S.R.; Jiang, H.; Hossain, M.B.; Fan, X.; Gumin, J.; Dong, A.; Alonso, M.M.; Gomez-Manzano, C.; Fueyo, J. Critical Role of Autophagy in the Processing of Adenovirus Capsid-Incorporated Cancer-Specific Antigens. PLoS ONE 2016, 11, e0153814. [CrossRef]

32. Ma, J.; Ramachandran, M.; Jin, C.; Quijano-Rubio, C.; Martikainen, M.; Yu, D.; Essand, M. Characterization of virus-mediated immunogenic cancer cell death and the consequences for oncolytic virus-based immunotherapy of cancer. Cell Death Dis. 2020, 11, 48. [CrossRef]

33. Anand, S.K.; Tikoo, S.K. Viruses as Modulators of Mitochondrial Functions. Adv. Virol. 2013, 2013. [CrossRef] [PubMed]

34. Rai, Y.; Pathak, R.; Kumari, N.; Sah, D.K.; Pandey, S.; Kalra, N.; Soni, R.; Dwarakanath, B.S.; Bhatt, A.N. Mitochondrial biogenesis and metabolic hyperactivation limits the application of MTT assay in the estimation of radiation induced growth inhibition. Sci. Rep. 2018, 8, 1531. [CrossRef] [PubMed] 